\title{
PENDAMPINGAN KOMERSIALISASI MINUMAN HERBAL BAGI PENGURUS DAERAH AISYIYAH KOTA MALANG
}

\author{
Endang Dwi Wahyuni ${ }^{1}$ \\ Eny Suprapti ${ }^{1}$ \\ Program Studi Akuntansi, Universitas Muhammadiyah Malang ${ }^{1}$
}

\begin{abstract}
Abstrak
Goals the activities to provide business motivation as well as assistance commercialization of herbal drinks for the Regional Board Aisyiyah Malang. Aisyiyah management already has a cooperative that can be used as a container to market their products. During this product sold in the cooperative quite a lot, among others: school uniforms, school equipment, snacks and various types of beverages. However, the products sold, there is no production of Aisyiyah citizens themselves. Therefore, it is necessary to motivate the herbal beverage business for the board and members to capture the existing business opportunities, while providing commercialization assistance. The results of direct training is practiced and sold at every bazaar event that is always held every activity conducted by Economic and Entrepreneurship Assembly, PDA Malang. Advisory activities are carried out directly whenever any complaints or obstacles are encountered, such as issues related to storage durability or expiration period, hygienic packaging, unpleasant taste, use / addition of other materials, etc.
\end{abstract}

Keywords: Business assistance, Business motivation, Herbal Drinking

\section{PENDAHULUAN}

Analisis Situasi

Pembangunan adalah suatu proses perubahan yang dilakukan secara kontinyu oleh suatu bangsa untuk meningkatkan taraf hidup dan kesejahteraan masyarakatnya. Kaum perempuan merupakan komponen bangsa yang dapat diberdayakan untuk peningkatan kesejahteraan keluarga. Kondisi di lapangan menunjukkan bahwa selama ini pengelolaan sumberdaya pedesaan sebagian besar dilakukan oleh laki-laki, mulai dari kegiatan di bidang pertanian, peternakan, industri kecil dan menengah, koperasi, dan kegiatan lain yang sifatnya kegiatan ekonomi. Perempuan sebagai anggota masyarakat juga mempunyai hak untuk ikut serta dalam pengelolaan sumberdaya pedesaan. Oleh karena itu diperlukan adanya berbagai program yang dapat dilakukan perempuan dalam rangka peningkatan kesejahteraan keluarga dengan dan mengelola lingkungan sekitarnya. Salah satu program yang dapat dilaksanakan oleh perempuan dalam upaya peningkatan kesejahteraan keluarga, adalah penggunaan tumbuhan obat sebagai bahan minuman herbal.

Pengembangan inovasi minuman herbal berawal dari ide pengembangan dan penggunaan produk non kimiawi yang saat ini lebih diminati masyarakat karena rendah efek samping. Tren di masayarakat yang menjalani kehidupan "back to nature" menjadi suatu penciptaan peluang pasar dan pangsa pasar yang strategis dalam pemasaran produk minuman herbal yang berkualitas. Usaha minuman herbal yang sudah banyak berkembang adalah minuman herbal beras kencur dan kunyit asam. Kenyataan yang ada di masyarakat, minuman herbal yang lain yang juga disukai adalah wedang uwuh. Kalau masyarakat Sunda lebih mengenal dengan sebutan bier pletok. Usaha minuman herbal bisa dikembangkan oleh masyarakat secara individu maupun berkelompok. Aisyiah sebagai organisasi sosial mempunyai kegiatan sosial yang cukup banyak, baik untuk pemberdayaan perempuan dan masyarakat luas di bidang pendidikan, sosial, dan kemasyarakatan. Tentunya untuk melaksanakan kegiatan tersebut memerlukan dana yang cukup banyak. Dana tersebut diperoleh dari iuran spontanitas pengurus dan anggota atau dari donatur dan simpatisan. Cara perolehan dana tersebut tidak dapat diandalkan keberadaannya seratus persen. Oleh karena itu, pengurus Aisyiah harus mulai memikirkan alternatif sumber dana lain, yaitu dengan mendirikan unit bisnis yang profit oriented. Pengurus Aisyiyah sudah mempunyai rintisan bisnis yaitu membuat minuman herbal. Tetapi sulit untuk berkembang, oleh karena itu tim pengabdian bermaksud untuk memberikan pendampingan komersialisasi bisnis minuman herbal ini agar produknya belih berkualitas dan mampu

\footnotetext{
${ }^{1}$ dwiwahyuni_endang@yahoo.co.id
} 
bersaing di pasaran.

Langkah awal yang perlu dilakukan adalah member motivasi bisnis bagi pengurus Aisyiyah. Tujuannya adalah memberikan motivasi usaha yang menjanjikan. Seperti yang kita ketahui, minuman herbal atau produk herbal lagi nge-trend di masyarakat dan diyakini sangat bermanfaat untuk kesehatan. Oleh karena itu motivasi bisnis lebih ditekankan pada peluang bisnis minuman herbal. Hal yang dipertimbangkan adalah proses produksinya relative mudah dan bahan-bahan yang dibutuhkan mudah dicari di pasaran. Langkah berikutnya adalah memberikan pelatihan pembuatan minuman herbal, dilanjutkan dengan pelatihan pembuatan kemasan yang menarik dan pemberian label.

Dengan pengabdian yang ditekankan di bidang produksi, diharapkan pengurus Aisyiyah dapat meningkatkan kualitas produk dan produktivitas serta produk dapat dikenal dan diterima konsumen dan masyarakat luas. Lebih penting lagi dari hasil usaha ini dapat digunakan untuk mendanai aktivitas sosial yang dilakukan Aisyiyah kota Malang. Dengan demikian pengurus Aisyiyah dapat mengamalkan dua hadits sekaligus, pertama, "Sembilan dari 10 pintu rezeki ada dalam perdagangan dan sepersepuluh ada dalam beternak domba" (HR. Sa'id bin Manshur). Tegasnya, usaha perdagangan mendapatkan peluang paling besar untuk memperoleh kekayaan atau rezeki dari Allah karena pintu rezeki yang Allah bukakan bagi usaha dagang lebih banyak daripada usaha-usaha lainnya.

\section{Masalah yang dihadapi Mitra} berikut:

Secara umum, permasalahan yang dihadapi oleh pengusaha kecil adalah digambarkan sebagai

1. Bagaimana membangun pengetahuan dan ketrampilan dalam pemanfaatan tanaman sampai menjadi produk minuman herbal melalui bermacam-macam kegiatan pelatihan dan keterampilan.

2. Melakukan pelatihan pembuatan minuman herbal dengan melibatkan ahli dari Dinas Kesehatan, sehingga minuman tersebut aman dikonsumsi masyarakat.

3. Melakukan Pendampingan kepada Pengurus Aisyiyah Kota Malang untuk membuat minuman herbal dan pemasarannya.

\section{Tujuan}

1. Tujuan pengabdian agar pengurus aisyiyah bisa mempunyai pengetahuan dalam pemanfaatan tanaman sampai menjadi produk minuman herbal melalui bermacam-macam kegiatan pelatihan dan keterampilan.

2. Pengusaha dapat memiliki keahlian dalam pembuatan minuman herbal yang sesuai dengan standar kesehatan, sehingga minuman tersebut aman dikonsumsi masyarakat.

3. Pengurus Aisyiyah memiliki keahlian dan ketrampilan dalam pembuatan dan pemasaran produk.

\section{MATERI DAN METODE PELAKSANAAN}

Metode pelaksanaan IbM untuk meningkatkan nilai tambah minuman herbal dalam kemasan siap minum dengan mekanisme sebagai berikut:

a. Sosialisasi Program pengabdian masyarakat kepada pengurus Aisyiyah Kota Malang

b. Trial and error dalam pembuatan minuman herbal

c. Pelatihan teknologi pembuatan Minuman herbal dalam kemasan

d. Teknik pengemasan minuman herbal untuk meningkatkan mutu dan harga jual dengan packing yang lebih berkualitas

Kegiatan utama adalah transfer teknologi pembuatan minuman herbal dalam kemasan. Pelatihan diikuti praktek pembuatan minuman herbal dalam kemasan oleh mitra IbM. Pelatihan yang diadakan 2 kali. Praktek pertama, dilakukan oleh Tim Pengabdian yang disaksikan dan dibantu oleh peserta. Praktik kedua, praktek secara mandiri oleh kelompok mitra didampingi oleh Tim Pelaksana dan dilakukan untuk meningkatkan ketrampilan praktis para mitra.

Adapun metode pendekatan dan prosedur kerja dalam pengabdian masyarakat ini adalah sebagai berikut: 
Tabel 1. Bentuk Kegiatan Pengabdian Masyarakat

\begin{tabular}{|c|c|c|}
\hline Nomor & Kegiatan & Hasil \\
\hline 1. & Sosialisasi program & $\begin{array}{l}\text { Pemahaman terhadap kegiatan yang akan } \\
\text { dilakukan }\end{array}$ \\
\hline 2. & $\begin{array}{l}\text { Teori dan praktek pembuatan minuman } \\
\text { herbal }\end{array}$ & $\begin{array}{l}\text { Didapatkan formula dan metode } \\
\text { pembuatan minuman herbal yang tepat } \\
\text { dilihat dari aspek bentuk, warna, } \\
\text { rasa,aroma dan keawetan produk } \\
\text { sehingga layak untuk dipasarkan }\end{array}$ \\
\hline 3. & Praktek pembuatan minuman herbal & $\begin{array}{l}\text { Kemampuan melakukan proses produksi } \\
\text { minuman herbal dalam kemasan }\end{array}$ \\
\hline 4. & Praktek pengemasan & $\begin{array}{l}\text { Memahami tehnik pengemasan } \\
\text { yanghigienis agar } \\
\text { menghasilkan produk yang berkualitas }\end{array}$ \\
\hline 5. & Analisis kelayakan usaha & $\begin{array}{l}\text { Memahami dan menganalisis hasil usaha } \\
\text { pembuatan minuman herbal, } \\
\text { menguntungkan atau tidak }\end{array}$ \\
\hline 6. & $\begin{array}{l}\text { Pendampingan dalam } \\
\text { minuman herbal }\end{array}$ & $\begin{array}{l}\text { Mengetahui pembuatan minuman herbal } \\
\text { yang dilakukan mitra sudah sesuai } \\
\text { dengan teori yang diberikan pada saat } \\
\text { pelatihan. }\end{array}$ \\
\hline 7. & $\begin{array}{l}\text { Pendampingan dalam } \\
\text { minuman herbal }\end{array}$ & $\begin{array}{l}\text { Mencarikan kegiatan yang ada bazaar dan } \\
\text { mempromosikan produk minuman herbal } \\
\text { yang diproduksi mitra }\end{array}$ \\
\hline
\end{tabular}

\section{HASIL DAN PEMBAHASAN}

a. Sosialisasi dan pelatihan pembuatan minuman herbal

Langkah pertama yang dilakukan adalah memberikan motivasi tentang pentingnya minuman herbal, dan menjelaskan bahan-bahan yangdigunakan relative mudah didapat, peralatan yang digunakan sederhana dan tidak perlu membeli peralatan khusus. Pemberian materi oleh tim pengabdian dan mendatangkan juga ahli pangan (ibu Elok Waziroh).

b. Praktik pembuatan minuman herbal

Pada saat melakukan praktik pembuatan minuman herbal, tim pengabdian dibantu peserta pelatihan mulai menimbang bahan, mencuci, serta memasak sampai menjadi minuman yang hangat dan menyehatkan.

Sirup Bir Pletok adalah suatu inovasi baru dimana tujuannya untuk meningkatkan daya guna dan daya jual produk lokal.

Bahan-bahan yang diperlukan dalam pembuatan minuman herbal sirup Bir Pletok yaitu: jahe, kayu secang, serai, merica, pandan, kayu manis dan gula.

Adapun manfaat dari bahan-bahan tersebut adalah:

1. Jahe: mengurangi mual, antidiabetes, menurunkan berat badan, mengobati migrain, dan antioksidan

2. Secang: antibakteri, antidiabetes, pewarna alami

3. Serai: meredakan nyeri haid, mengobati gangguan pencernaan, detoksifikasi, antioksidan dan menurunkan tekanan darah

4. Merica: menurunkan berat badan, meredakan sakit perut, menurunkan tekanan darah tinggi, dan antioksidan

5. Pandan: memberikan bau wangi, mengobati rematik, pegal linu, lemah syarah, dan mengatasi gelisah

6. Kayu manis, manfaatnya menurunkan kadar gula darah dan meningkatkan stamina.

c. Proses Produksi

Pengolahan minuman herbal sirup Bir Pletok memerlukan 3 tahapan.

1. Tahap persiapan

Siapkan panic dan panaskan air dalam panci

Bakar / panaskan jahe -> dikeprak

Serai dikeprak 
2. Proses Pembuatan

Pembuatan sirup bir pletok cukup mudah, pertama, bahan-bahan (Jahe, serai, pandan, merica, kayu manis) dimasukkan dalam panci yang telah terisi air panas

Tambah gula kedalam ramuan

Tunggu sampai aroma rempah keluar

Setelah mendidih, sisihkan rempah -rempah

3. Proses pemekatan

Bir Pletok yang telah diperoleh dipanaskan kembali dalam api kecil

Ditambahkan 60\% gula untuk meningkatkan kekentalan

Aduk ramuan selama proses pemekatan agar tidak terbentuk kristal gula

Tunggu hingga bir pletok mengental

4. Proses Pengemasaan

Sirup Bir Pletok yang didapat di tunggu hingga dingin

Botol pengemas di sterilisasi

Tuang sirup kedalam botol

Beri label agar meningkatkan daya jual produk.

d. Analisis kelayakan usaha minuman herbal

Bisnis dikatakan layak jika bisnis tersebut dapat memberikan keuntungan. Maka sebelum bisnis dimulai, perlu dilakukan analisis kelayakan. Berikut ini hasil analisis yang dilakukan bisa memberikan keuntungan Rp. 191.000,- atau 53\%. Berdasarkan perhitungan tersebut, bisnis minuman herbal sirup bir pletok sangat layak untuk dilakukan.

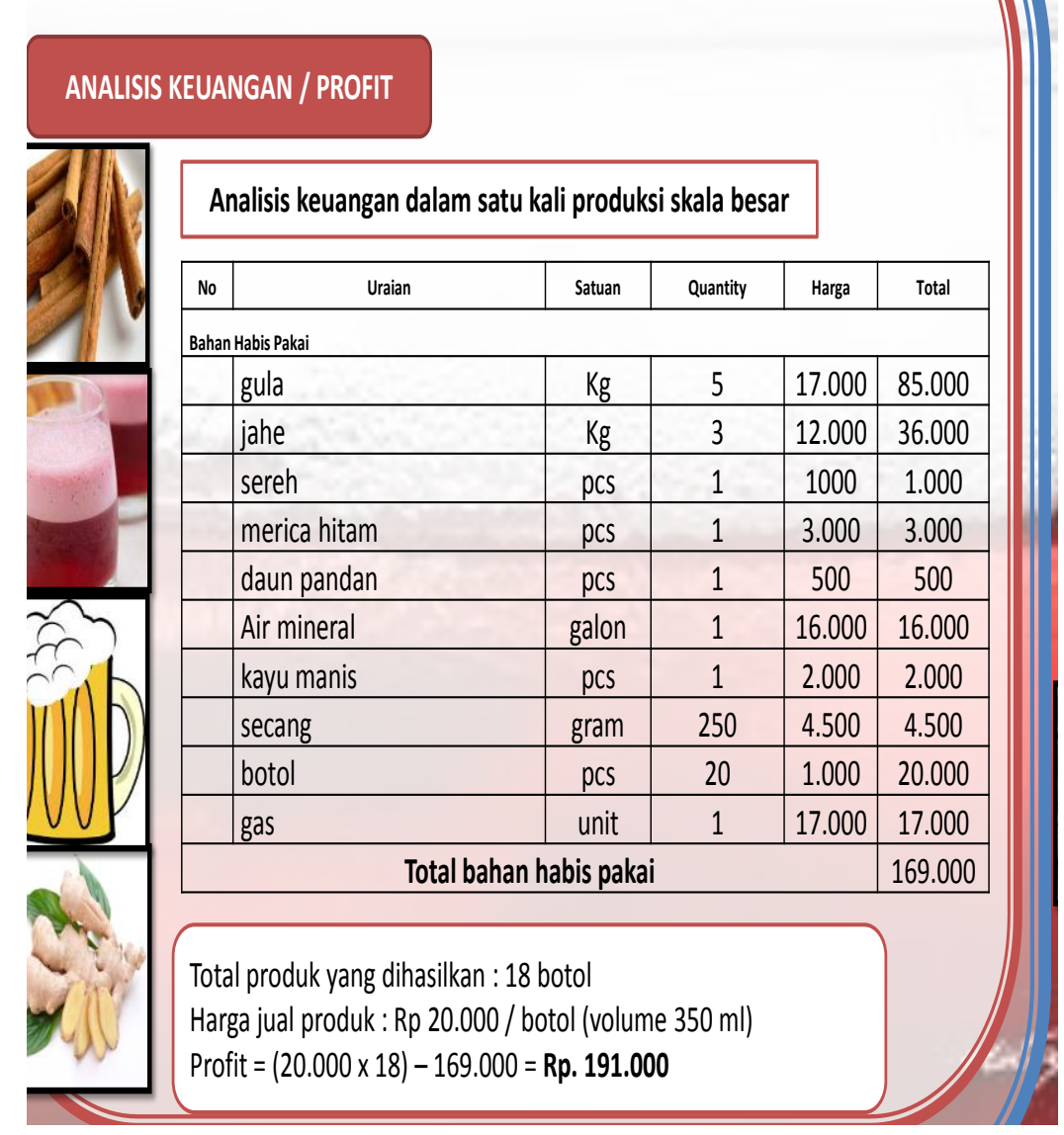




\section{KESIMPULAN}

Kegiatan pengabdian dilakukan dengan melakukan sosialisasi kegiatan, pemberian materi dan praktik pembuatan minuman herbal, dan analisis kelayakan usaha.

\section{UCAPAN TERIMAKASIH}

Pada kesempatan ini saya sangat bersyukur diberi kesempatan untuk bisa sharing ilmu dan pengalaman dengan Pengurus Majelis Ekonomi dan Kewirausahaan PDA Kabupaten Malang. Terima kasih atas bantuan dan partisipasinya. Dan yang tak terlupakan pimpinan FEB UMM yang telah memberi motivasi, dan dukungan moral dan material.

\section{REFERENSI}

Anonim, 2010, Herbal Indonesia Berkhasiat, Vol.10, Trubus, Jakarta, Indonesia.

Badan Pengawas Obat dan Makanan R.I, 2010, Acuan Sediaan Herbal, Vol 5, Badan POM RI

Jakarta.

Badan Pengawas Obat dan Makanan RI, 2012, Petunjuk Operasional Penerapan Cara

Pembuatan Obat yang Baik, Jilid 2, Badan POM RI, Jakarta.

Kementerian Perindustrian, 2014, Kosmetika dan Herbal Menghadapi MEA 2015, Jakarta. 
